\title{
Living in a rural area with advanced chronic respiratory illness: a qualitative study
}

\author{
*Donna Goodridge ${ }^{a}$, Shelly Hutchinsona, Donna Wilson ${ }^{b}$, Carolyn Ross ${ }^{b}$ \\ a University of Saskatchewan, College of Nursing, Saskatoon, Saskatchewan, Canada \\ ${ }^{\mathrm{b}}$ Faculty of Nursing, University of Alberta, Edmonton, Alberta, Canada
}

Received 4th January 2010; revised version received 18th January 2010; accepted 20th July 2010; online 24th September 2010

\begin{abstract}
Aim: To explore the impact of living with advanced chronic respiratory illness in a rural area

Methods: Using an interpretive descriptive approach, semi-structured interviews were conducted with seven people living with advanced chronic respiratory illness in a rural area of Western Canada.

Results: Themes that characterised the experience of living in a rural setting with a chronic obstructive respiratory illness included: a) distance as a barrier to accessing health care; b) relationships with family practice physicians; c) supportive local community; and d) lack of respiratory education and peer support.

Conclusions: Whilst living with advanced respiratory illness in a rural area posed some significant challenges, experiences of "place", conceptualised as a web of relationships embedded within a local context, are an important factor in rural residents' decisions to remain in situations where distance may present significant challenges to accessing health care.

(C) 2011 Primary Care Respiratory Society UK. All rights reserved.

D Goodridge et al. Prim Care Respir J 2011; 20(1): 54-58

doi:10.4104/pcrj.2010.00062
\end{abstract}

Keywords primary care, COPD, chronic, respiratory, illness, qualitative, rural healthcare

\section{Introduction}

Living with a chronic obstructive respiratory illness presents many challenges ${ }^{1}$ that may be compounded by residing in a rural area. Compared to people living in urban settings, rural residents have an increased risk of mortality associated with incurable and often progressive respiratory diseases such as chronic obstructive pulmonary disease (COPD). ${ }^{2}$ Decreased access to health services within rural communities, geographic isolation, closure of local hospitals and nursing homes, and extended travel time to urban hospitals for disease management, are system factors that contribute to the poorer health status of rural residents. ${ }^{2}$

Living well with advanced respiratory illness depends to a large extent on the patient's ability to manage symptoms and cope with the limitations imposed by the illness. ${ }^{3}$ The Chronic Care Model (CCM) ${ }^{4,5}$ a comprehensive approach which has been widely adopted as a means of improving management and outcomes in chronic illness, emphasises the involvement of informed, activated patients who are situated within a context of supportive community resources and a well-organised health care system. Rural healthcare is substantively different from urban settings, potentially creating a different set of challenges for those living with respiratory disease in rural environments.

Evidence on the effect of rural settings on overall health care access and utilisation is inconclusive. ${ }^{6}$ No differences between rural and urban residents have been reported with regard to use of physician services, hospitalisation rates, ${ }^{7.8}$ unmet health care needs, or number of days required to obtain appointments. ${ }^{9}$ However, several notable differences between rural and urban health care utilisation have been reported. Rural residents were more likely than those in urban areas to have a usual source of primary care, but had fewer visits to health care providers. ${ }^{10}$ Hospitalisations for ambulatory-care sensitive conditions (ACSC) such as COPD that can be potentially managed and controlled in community settings, appear to be positively associated with increasing levels of rurality, suggesting rural-urban disparities in

\footnotetext{
* Corresponding author: Dr Donna Goodridge, University of Saskatchewan, College of Nursing, 103 Hospital Drive, Saskatoon, Saskatchewan S7N 0W3 Canada. Tel: +1 (306) 966-1478 E-mail: donna.goodridge@usask.ca
} 
access to primary health care. ${ }^{11}$

Successful management of chronic respiratory illness in rural settings may also be compromised by lack of access to services such as peer support groups ${ }^{12}$ and pulmonary rehabilitation programs. ${ }^{13}$ Because there are often insufficient numbers of individuals living with a particular illness to sustain a peer support group in a given rural area, long-distance travel to a face-to-face meeting may limit access. ${ }^{12}$ Although the positive patient outcomes of pulmonary rehabilitation programs have been well demonstrated, a national survey suggested that only $1.2 \%$ of the overall Canadian population with COPD had access to these programs. ${ }^{13}$ This lack of access is likely amplified in rural areas; rural residents of Colorado were significantly less likely to participate in pulmonary rehabilitation programs than those in urban areas. $^{14}$

There are few published studies examining the experience of living with a chronic respiratory illness within a rural context. Sullivan and colleagues ${ }^{15}$ explored the experiences of rural women living with a chronic illness. The rural environment was found to complicate women's abilities to adapt to their conditions because of limited health care services, need to travel long distances for treatment, and feelings of loneliness and isolation. Similar findings were reported by Fitzgerald and colleagues in an Australian study. ${ }^{16}$ A descriptive ethnography reported that living in a rural area with chronic illness was a relational experience in the context of the whole community, rather than the effect of pathology alone. ${ }^{17}$

This exploratory, qualitative study was guided by the research question, "What is the impact of living with advanced chronic respiratory illness in a rural area?"

\section{Methods}

An interpretive descriptive approach enhances our understanding of clinical phenomena and was therefore used to analyse the interview data. ${ }^{18}$ This methodology acknowledges the constructed and contextual nature of human experience. ${ }^{19}$

Following approval to conduct this study by the affiliated institutional Behavioral Ethics Review Committee, participants were recruited by Home Care nurses in a rural health region in Western Canada. This health region encompasses an area of more than $40,000 \mathrm{~km}^{2}$, has population densities ranging from 1.1-2.0 persons per $\mathrm{km}^{2}$ and is designated as having no metropolitan influence (between 0 - 40 of the employed labour force commute to work in centres with populations greater than 10,000) by Statistics Canada. ${ }^{20}$ The climate is considered extreme, with standard temperature variations of more than 65 deg Celsius within any one year. ${ }^{21}$

Inclusion criteria included: a) having a confirmed medical diagnosis of moderate to severe obstructive respiratory disease; b) residing within the boundaries of the specified health region; c) not being a resident of a special care or nursing home); d) understanding and speaking English; e) being competent to provide informed consent to participate in the study; and f) receiving some form of home care assistance. Seven participants who met the study criteria were recruited though the Home Care nurses approaching patients. Written consent to participate in the study was obtained.

\section{Data collection}

Data collection for this study involved face-to-face semistructured interviews conducted in the participants' homes. All interviews were audiotaped and conducted by a trained research assistant who was an experienced registered nurse and certified respiratory educator. The interview schedule comprised open-ended questions in which participants were asked to describe their experiences of living as a rural resident with chronic respiratory illness. Each interview lasted between 35 and 60 minutes.

\section{Data analysis}

Qualitative data were transcribed verbatim, and transcriptions were checked and then entered into a qualitative data management program. The interpretive descriptive approach allowed the unique aspects of each person's experience to be examined in depth and in context. ${ }^{18}$ Two of the investigators independently examined the transcripts first to code and analyse the data manually, with subsequent meetings to achieve consensus. Data patterns including main points and topics were identified, and from these major themes emerged. Raw data, field notes, and memos were retained to assist in providing an audit trail.

\section{Results}

Seven individuals aged 57 to 88 years living in rural Western Canada participated in this study. While each of the participants resided in different small towns, they were all long-term residents of their community with the exception of P5, who had moved to the town just three years previously. Six of the participants were female. Six had a diagnosis of COPD, and one had bronchiectasis. All experienced moderate to severe dyspnoea and were receiving long-term oxygen therapy (LTOT). Table 1 displays demographic and clinical variables for each participant.

Participants recognised that health care in the rural context in which they lived was different from the health care available in urban settings, and had both drawbacks and benefits. Whilst there were challenges that influenced the way in which they lived with chronic respiratory illness in their rural environment, participants emphasised the supports and adaptations that allowed them to manage their illness to the best of their abilities. Four major themes emerged from the analysis that characterised the experience of living in rural setting with a chronic obstructive respiratory illness: 
Table 1. Demographic and clinical description of participants.

\begin{tabular}{llcccccc} 
& Diagnosis & Sex & Age & Marital Status & $\begin{array}{c}\text { Number of } \\
\text { comorbid conditions }\end{array}$ & $\begin{array}{c}\text { Living } \\
\text { Arrangements }\end{array}$ \\
\hline P1 & COPD & F & 67 & Divorced & 5 & Alone & 3 \\
\hline P2 & COPD & M & 70 & Divorced & 2 & Alone & 4 \\
\hline P3 & COPD & F & 82 & Divorced & 6 & Alone & Alone \\
\hline P4 & COPD & M & 83 & Widowed & 8 & Alone \\
\hline P5 & Bronchiectasis & F & 76 & Widowed & 4 & With spouse \\
\hline P6 & COPD & F & 88 & Married & 5 & With spouse & 4 \\
\hline P7 & COPD & F & 57 & Married & 1 & 3
\end{tabular}

a) distance as a barrier to accessing health care;

b) positive relationships with primary healthcare providers;

c) supportive local community; and

d) lack of respiratory education and peer support.

Distance as a barrier to accessing health care

Distance was a key challenge to accessing health care for these rural participants. All of the participants commented on the long distances they needed to drive for appointments, to buy groceries, or for recreation. P4 remarked;

"The worst part is travel. You've got appointments in [major city about four or five hours away], appointments in [larger town about two hours away]... So many people, city people, don't realise the miles we drive. It's amazing the miles we pile on."

The challenges imposed by travelling long distances meant that driving a vehicle was critically important to accessing health care. Most of the participants still drove and were proud of being able to maintain their independence. Participants made extraordinary efforts to retain the independence that was afforded by driving. Those who continued to drive would leave a spare oxygen tank in the car as they were too weak to carry it from the house to the care, and required continual oxygen while driving.

Taxis and public transportation were not widely available in this rural area, although one of the participants (P6) had been a volunteer driver who drove people around her own local community to appointments. Those who did not have access to such a volunteer service within their community or who did not themselves drive had to wait and depend on the good will of family and friends when they needed to access health care.

The requirement to travel long distances for health care made some participants reluctant to seek care, even in urgent situations. When P2 experienced an exacerbation of his COPD, he phoned the local hospital. He was instructed to call an ambulance and go to a neighboring town's hospital 30 minutes away because it was the local doctor's weekend off. After hearing this, P2 decided to return home and took a few tablets of dimenhydrinate so he could sleep;

"My daughter came over a day later...I wasn't even in shape to walk out to her car...they got the ambulance... I spent...ten days at the hospital and had every test and every doctor in the university looked after me."

There were no difficulties experienced by any of the participants with accessing oxygen or other respiratory supplies as a result of living in a rural area. P1's response was representative of this group when she indicated that;

"we have a place I can go get oxygen if I run out . downtown."

Positive relationships with primary healthcare providers Primary care providers, including family physicians and nurse practitioners, were critical resources in participants' selfmanagement of their respiratory illnesses. All of the participants noted that one of the benefits of accessing health care in a rural setting was personalisation of care based on their knowledge of the patient as a person. P2 described the importance of family physicians having a relationship with their patients;

"There been doctors here, they come and go like the wind... they don't really know you...Dr. L [long-term local doctor] has known me all my life and he's preached to me and preached to me to quit smoking".

P6 felt that health care was of better quality in the rural setting than it was in the bigger cities;

"People know people...it's more of a big family...In the city, you're a number as far as I'm concerned. Like if I get sent to the city... it's just a quick go and then bye and that's the end of it - you never hear from them again, where that isn't like that here".

P3 believed that rural physicians had more time than urban physicians;

"I think you get personal care here because the city, they're so swamped... How can they do a good job doctoring when they only have 15 minutes for you?". She went on to describe how her physician came to her home when she wasn't feeling well;

"He knocked on the door and here was the doctor...I said...you look like a guardian angel... He tested my chest and said 'you go straight to the hospital'." 
The rural family physician shortage was felt acutely, as these participants rarely ventured to urban centres for appointments with respirologists and depended almost exclusively on the local family physicians. P5, in speaking of the fact that her town had lost its only doctor, commented that;

"in these smaller towns, it's our own fault because when we had doctors here...people didn't think anything of phoning them at night."

P6 had a somewhat different perspective on family physicians' short tenure in rural areas;

"He was too good. He left...we've had two or three since then...and they just stay two years...and then they're gone... [The current physician] is going away right now to do more school".

Participants were unanimous in their overall satisfaction with the health care they received as rural residents related to their chronic respiratory illnesses. P2 expressed her expectations about health care in the following way;

"As long as you got oxygen, what else do you need, really? I don't know what the city can do that they can't do here. What can they do other than give me air?"

\section{Supportive local community}

Participants were both proud and appreciative of the support offered within their local communities. Coping with a chronic respiratory illness was made easier by the availability of family, friends and businesses who made special efforts to address the needs of participants. P1 had an elderly friend that she found very helpful;

"If I'm running short of breath, she knows, she never panics...she always just says, well, just slow down... she's very good with me that way."

In particular, the support of neighbours was something that P3 felt was unique to the rural setting:

"There a neighbour up the street, she'll say, 'M. I'll take you. You know that..you don't get this in the city, you're on your own."

When an emergency occurred for P4;

"I called the lady up the road and... they were here, like in, it seemed like three minutes."

P3 noted;

"I haven't been out [of the house] for a year... I go through the flyers and order what I want and they [grocery store] deliver. For a dollar. You can't get that in the city".

Lack of respiratory education and support

Access to pulmonary education and peer support was perceived by participants as one of the few shortcomings related to living with respiratory illness in a rural area. P7's perspective was that;

"the cities have a lot more options. Rural [province] has nothing to offer people who have COPD...I don't think they educate you enough".
This participant felt that her care providers were not always wellinformed - she had to inform the home care staff that there was a toll-free telephone assistance line for people with COPD;

"I wish there was little bit more 'cause there's a few of us around town...I should start a COPD society maybe."

P1 echoed these sentiments;

"If you want information, you know, you've got to dig

for it... there's nothing offered to you in a small town."

This participant had also mentioned wanting to attend a rehabilitation program;

"but it wasn't available to me because I live in the rural area... But just to be able to talk to one or two people, even, would be just wonderful... [people] that are in the same position".

P7 was the only participant to have attended a pulmonary rehabilitation program; she had to travel several hours to a major city and stayed with her daughter in the city during part of the week so that she could access at least some of this program;

"I started with the exercise program and went there for about three months... and then it got to be winter and it's hard for me... I would go up and stay Monday to Wednesday and then I wouldn't take Friday".

-This participant continued to walk outside in the summer, pulling her oxygen tank down the dusty gravel road. The onset of winter and snow put a stop to this activity. The harsh winter and sometimes treacherous driving conditions kept this participant in her rural home, but P7 returned to the program in the spring for more education;

"the exercise was good and kept me going."

\section{Discussion}

Whilst the rural area had both advantages and disadvantages for self-management of advanced chronic respiratory illness, the participants in this study were generally very positive about living where they did. The challenges that were presented by extensive travel, erratic physician availability and lack of local respiratoryrelated education and support seemed to be offset by the benefits of being known and supported within their own communities.

Although increased health care needs have been demonstrated to be a key determinant of relocation to urban settings where care is more accessible, ${ }^{22}$ participants in this study did not plan to move and did not identify their health care to be compromised in ways that were unacceptable to them. Experiences of "place", conceptualised as a web of relationships embedded within a local context such as a rural community, ${ }^{23}$ are increasingly understood to be an important factor in rural residents' decisions to remain in situations where distance may present significant challenges to health care. Participants in this study demonstrated that 'place', ("This is home to me...") can in 
fact be more important than 'distance', in choosing to remain in rural settings..$^{24}$

Participants' perceptions of higher levels of community support in rural settings have been confirmed in other studies. ${ }^{25,26}$ Compared to urban dwellers, rural residents are also more likely to see relatives on a more regular basis, know and trust their neighbours, volunteer, and have a sense of community belonging. ${ }^{27}$ The literature relating to health care of rural residents suggests that there may be a differential perception of need and a reduced expectation for primary care among rural residents compare to urban counterparts. ${ }^{24}$ This difference may help to explain participants' acceptance of limited physician availability.

Given the dearth of literature relating to living with advanced respiratory illness in a rural setting, this study was a first step and thus exploratory in nature. The sample size of seven participants, while small, was sufficient to provide rich data addressing the research question. Participants were recruited from a single health region in Western Canada and their experiences may not reflect the experiences of persons in other rural settings.

\section{Conclusions}

Living with advanced respiratory illness in a rural area posed challenges that would not commonly occur in urban areas, including extensive travel required to access health care, erratic local physician availability and lack of respiratory-related education and support. Participants in this study, however, did not feel their health was compromised by rural residency and, in fact, were very positive about the advantages of rural areas in helping them to live with their illness.

\section{Conflict of interest}

The authors have no conflicts of interest to declare.

\section{References}

1. Wilson D, Ross C, Goodridge D, Davis P, Landreville A, Roebuck K. The care needs of community-dwelling seniors suffering from advanced Chronic Obstructive Pulmonary Disease. Can J Aging 2008;27(4):347-57. http://dx.doi.org/ 10.3138/cja27.4.347.

2. Canadian Institute for Health Information. How healthy are rural Canadians? An assessment of their health status and health determinants. Ottawa, ON: Government of Canada, 2006.

3. Bourbeau J, Nault D. (2007). Self-management strategies in Chronic Obstructive Pulmonary Disease. Clin Chest Med 2007;28:617-28. http://dx.doi.org/ 10.1016/j.ccm.2007.06.002

4. Bodenheimer T, Wagner EH, Grumbach K. Improving care for patients with chronic illness. JAMA 2002;288:1775-9.

5. Barr VJ, Robinson S, Marin-Link B, et al. The Expanded Chronic Care Model: an integration of concepts and strategies from population health promotion and the Chronic Care Model. Hospital Quarterly 2003;7:73-82.

6. Institute of Medicine. Quality through collaboration: the future of rural health. National Academies Press, Washington, DC:2005.
7. Himes CL, Rutrough TS. Difference in the use of health services by metropolitan and nonmetropolitan elderly. J Rur Health 1994;10:80-8. http://dx.doi.org/ 10.1111/j.1748-0361.1994.tb00214.x

8. McConnel CE, Zetzman MR. Urban.rural differences in health service utilization by elderly persons in the United States. J Rur Health 1993;9:270-80. http://dx.doi.org/10.1111/j.1748-0361.1993.tb00523.x

9. Reschovsky JD, Staiti AB. Access and quality: does rural America lag behind? Health Affairs (Millwood) 2005;24:1128-39. http://dx.doi.org/10.1377/hlthaff.24.4.1128

10. Larson SL, Fleishman JA. Rural-urban differences in usual source of care and ambulatory service use. Med Care 2003;41(III):65-74.

11. Laditka JN, Laditka SB, Probst JC. Health care access in rural areas: evidence that hospitalization for ambulatory-case sensitive conditions in the United States may increase with the level of rurality. Health Place 2009;15:731-40. http://dx.doi.org/10.1016/j.healthplace.2008.12.007

12. lacovelli M. Self-help groups in rural areas of Canada. Retrieved Dec. 9, 2009 at www.selfhelp.on.ca/resource/Ruralshreport.pdf

13. Brooks D, Sottana R, Bell B, Hanna M, Laframboise L, Selvanayagarajah S, Goldstein R. Characterization of pulmonary rehabilitation programsin Canada in 2005. Can Respir J 2007;14:87-92.

14. Linderman DJ, Koff PB, Min SJ, et al. Rural/urban health and treatment disparities in advanced Chronic Obstructive Pulmonary Disease. Retrieved Dec. 9, 2009 at http://meeting.chestpubs.org/cgi/content/abstract/136/4/90S-a

15. Sullivan T, Weinert $C$, Cudney S. Management of chronic illness: voices of rural women. J Adv Nurs 2003;46:566-74. http://dx.doi.org/10.1046/j.03092402.2003.02846.x

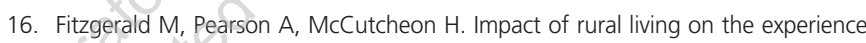
of chronic illness. Austral J Rur Health 2001;9:235-240. http://dx.doi.org/ 10.1046/j.1440-1584.2001.00398.x

17. Davis R, Magilvy JK. Quiet pride: the experience of chronic illness by rural older adults. J Nurs Schol 2000;32:385-90. http://dx.doi.org/10.1111/j.15475069.2000.00385.x

18. Thorne S. Interpretive description. Walnut Creek, CA: Left Coast Press, 2008.

19. Thorne S, Reimer Kirkham S, O'Flynn-Magee K. The analytic challenge in interpretive description. Int J Qual Meth 2004;3:1-21.

20. Statistics Canada. Census metropolitan area and census agglomeration influenced zones (MIZ). Retrieved Dec. 9, 2009 at www.statcan.gc.ca/concepts/definitions/hrrs2007-eng.htm

21. Government of Saskatchewan. The encyclopedia of Saskatchewan: climate. Retrieved December 14, 2009 at http://esask.uregina.ca/entry/climate.html

22. Sabia JJ. There's no place like home: a hazard model of aging in place among older homeowners in the PSID. Res Aging 2008;30:3-35. http://dx.doi.org/ 10.1177/0164027507307919

23. Nemet GF, Bailey AJ. Distance and health care utilization among the rural elderly. Soc Sci Med 2000;50:1197-2008. http://dx.doi.org/10.1016/S02779536(99)00365-2

24. Goodman DC, Fisher E, Stukel TA, Chang C. The distance to community medical care and the likelihood of hospitalization: Is closer always better? Am J Pub Health 1997;87:1144-50. http://dx.doi.org/10.2105/AJPH.87.7.1144

25. Mayer ML, Slifkin RT, Skinner AC. The effects of rural residence and other social vulnerabilities on subjective measures of unmet need. Med Care Res Rev 2005;62:617-28. http://dx.doi.org/10.1177/1077558705279315

26. Strickland J, Strickland DL. Barriers to preventive health services for minority households in the rural South. J Rural Health 1996;12:206-17. http://dx.doi.org/10.1111/j.1748-0361.1996.tb00795.x

27. Turcotte, Martin. (2005). Social engagement and civic participation: Are rural and small town populations really at an advantage? Rural and Small Town Analysis Bulletin 2005;6(4):124-8.

Available online at http://www.thepcrj.org 